\title{
Research on the Financial Development Scale, Efficiency and Poverty Reduction in Ethnic Areas of China
}

\author{
Jianqiong Peng ${ }^{1,2, a, ~}$, Zhoubo Wang ${ }^{2,3, ~ b}$ \\ ${ }^{1}$ Southwest Minzu University, Chengdu, Sichuan, 610041, China \\ ${ }^{2}$ Yangtze Normal University, Fuling, Chongqing, 408100, China \\ ${ }^{3}$ Sichuan University, Chengdu, Sichuan, 610065, China \\ jjingdu6@163.com, belenawongsh@126.com \\ *Corresponding author: Jianqiong Peng
}

Keywords: financial development scale; efficiency; poverty reduction; ethnic areas

\begin{abstract}
Using the panel data from 2000 to 2016, this paper analyzes the relationship between financial development efficiency, scale and poverty reduction in ethnic areas of China. It is found that the scale of financial development is positively correlated with poverty reduction, while financial development efficiency is negatively correlated with it. Economic growth, industrial structure, urbanization level, fixed asset investment and poverty alleviation are significantly positively correlated. It is proposed that financial institutions should adjust their business models, innovate financial products, and increase their support for regional industries.
\end{abstract}

\section{Introduction}

In recent years, China's poverty alleviation work in ethnic areas has achieved great results. However, due to poor infrastructure and foundations for poverty alleviation, ethnic areas have a high rate of returning to poverty. Therefore, poverty areas in ethnic areas are the key and difficult areas for China's poverty alleviation. It is a short-board area for building a well-off society in an all-round way. Complementing these short boards is the key to winning the fight against poverty. Understanding the role of financial development in poverty alleviation in ethnic areas is very important to promote the financial reform、 give full play to the driving effect of financial poverty alleviation, and promote the comprehensive realization of a well-off society in ethnic areas.

\section{Research review}

Few foreign scholars have studied the relationship between financial development and poverty alleviation in ethnic areas, but the related research is rich, mainly focusing on the direct and indirect effects for poverty alleviation. Burgess et al. (2004) found that for every $1 \%$ increase in the number of banking institutions in ethnic minority areas of India, the incidence of poverty would be reduced by $0.34 \%$.Claessens S, Feyen (2016) argued that financial services can increase the opportunities and access of the poor to accessing funds. Therefore, increasing the accessibility of financial services for the poor is conducive to poverty alleviation. Beck, Demorguc-Kunt\&Levine (2007) believed that financial development can promote economic growth reduce the income gap between the rich and the poor and the proportion of the poor.

Chinese scholars have also made many research on the anti-poverty effects for financial development. Jiangang Peng\& Guanzheng Li (2006) believed that small and medium-sized financial institutions should be vigorously developed to raise farmers' income levels. Yongbin Lv\&Peipei Zhao (2014) empirically found that the scale of financial development is conducive to poverty alleviation, while the efficiency of financial development is not conducive. Tingting Xie\&Yanfang Guo (2016) measured the financial anti-poverty efficiency and found the financial anti-poverty efficiency and its influencing factors are different. Zhaoyang Lu (2016) found that the 
financial poverty alleviation effect in ethnic areas is significant.

We found that many research supported that financial development can promote poverty alleviation; however, the conclusions are different because of the different selected objects and empirical methods. Based on the data for the seven ethnic provinces and areas of China from 2000 to 2016, this paper uses the panel model to analyze the impact of financial development on poverty alleviation, so as to find a more suitable method for financial poverty alleviation in ethnic areas.

\section{Model construction}

\subsection{Model and variable description.}

Model setting. In order to test the relationship between financial development and poverty alleviation in ethnic areas, this paper builds the following panel model based on the previous scholars' research:

$$
\ln p o v_{i t}=\alpha_{0}+\alpha_{1} f i n_{i t}+\alpha_{2} \ln g d p_{i t}+\beta_{i} x_{i t}+\mu_{i t}
$$

Where

$\ln \operatorname{pov}_{i t}, f i i_{i t} \ln g d p_{i t} \times x_{i t}$

means poverty reduction, financial development level, economic growth and other control variables, respectively. $\alpha_{0}, \alpha_{1}, \alpha_{2}, \beta_{i}$ means the estimate parameters, $\mu_{i}$ means the error term, and $i, t$ represents the region and time, $i=1,2, \ldots 7 ; t=2000,2001, \ldots 2016$.

Variable description. Poverty reduction $\left(\ln p o v_{i t}\right)$. Considering that most of the poverty areas are currently in rural areas of ethnic areas, this paper selects the per capita consumption level of rural areas with its natural logarithm to indicate the poverty reduction in ethnic areas based on Cui Y.J(2014). A higher value of lnpov ${ }_{i t}$ for a greater degree of poverty reduction.

Financial development level $\left(f i n_{i t}\right)$ : Divided into financial development scale $\left(f i n s_{i t}\right)$ ((Total deposits and loans) /GDP) and financial development efficiency (fine $e_{i t}$ ) (savings / loan).

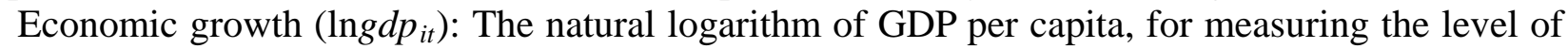
regional economic development in each region.

Control variables $\left(x_{i t}\right)$, including: industrial structure (agr), urbanization rate (czh), education level (edu), regional fixed asset investment with its natural logarithm (lngdzc). This paper measures the industrial structure by the proportion of total agricultural output value to GDP. Since the poverty areas is mainly distributed in rural areas, agriculture is an important source of income. The ratio of urban population to total population is used to measure the population urbanization rate (czh). Since the education expenditure in ethnic areas mainly comes from finance, this paper expresses the education level by the proportion of education expenditure to fiscal expenditure.

\subsection{Data source.}

Table 1 Descriptive statistics of each variable

\begin{tabular}{cccccc}
\hline Variable & Obs & Mean & Std. Dev. & Min & Max \\
\hline lnpov & 119 & 7.9689 & 0.5517 & 7.0211 & 9.2013 \\
fins & 119 & 2.5319 & 0.6016 & 1.4003 & 4.3343 \\
fine & 119 & 1.2374 & 0.1834 & 0.8038 & 1.9102 \\
lngdp & 119 & 9.3583 & 0.6272 & 7.9226 & 10.8717 \\
agr & 119 & 0.1486 & 0.0799 & 0.0567 & 0.7926 \\
czh & 119 & 0.4031 & 0.0908 & 0.2336 & 0.6120 \\
edu & 119 & 0.1926 & 0.0517 & 0.0990 & 0.3027 \\
lngdzc & 119 & 6.1805 & 0.5682 & 5.0423 & 6.9194 \\
\hline
\end{tabular}

Based on the previous research, according to the availability and consistency of the data, this paper selects panel data of ethnic regions (Inner Mongolia, Guangxi, Guizhou, Yunnan, Qinghai, Ningxia, Xinjiang) from 2000 to 2016; this article excluded Tibet due to serious data loss. All of the 
data is mainly derived from the "China Statistical Yearbook" over the years, the statistical yearbooks of seven provinces and regions, and the statistical bulletins of seven provinces and regions. All currency metrics have been adjusted based on the 2000 year to eliminate the impact of price fluctuations. Descriptive statistics of related variables are shown in Table 1.

\section{Model estimation and testing}

\subsection{Multiple collinearity test.}

The variance expansion factor (VIF) is used to test whether panel data has multiple collinearity. If VIF $>10$, it indicates that there is severe multicollinearity. The variance expansion factors of all explanatory variables are less than 10 (shown in Table 2), which means there is no serious multicollinearity problem between explanatory variables.

Table 2 Variable multicollinearity test

\begin{tabular}{|c|c|c|c|c|c|c|c|}
\hline Variable & fins & fine & $\operatorname{lngdp}$ & agr & $c z h$ & edu & $\operatorname{lngdzc}$ \\
\hline VIF & 1.65 & 2.08 & 5.39 & 1.27 & 5.43 & 4.23 & 4.14 \\
\hline
\end{tabular}

\subsection{Panel unit root test.}

Using the LLC (Levin-Lin-Chow) method performs a unit root test on the panel data, the results show that each of the main variables can reject the null hypothesis of the unit root at the commonly used level of significance. At the same time, as the data time span is relatively short, we believe that each regression variable in the model is a stationary sequence, and its level values can be included in the regression model.

\subsection{Inspection of model setting form.}

For the regression of the mixed panel data, the setting form of the panel model needs to be selected between the fixed effect model and the random effect model, the main method is through the Housman test. Using the Housman test, the model setting forms of the relationship between poverty alleviation and financial development scale and financial development efficiency are tested, espectively. The results show that It can reject the null hypothesis of random effect is better than fixed effect at $1 \%$ significance level. So fixed effect models should be used in the analysis.

\subsection{Regression analysis.}

Table 3 Fixed effect model regression results

\begin{tabular}{|c|c|c|}
\hline & (1) & (2) \\
\hline & lnpov & lnpov \\
\hline fins & $\begin{array}{c}0.151^{* * *} \\
(0.0332)\end{array}$ & \\
\hline lngdp & $\begin{array}{c}0.554^{* * *} \\
(0.0791) \\
\end{array}$ & $\begin{array}{c}0.601^{* * *} \\
(0.0877)\end{array}$ \\
\hline agr & $\begin{array}{c}0.333^{* *} \\
(0.131)\end{array}$ & $\begin{array}{c}0.288^{* *} \\
(0.141)\end{array}$ \\
\hline czh & $\begin{array}{c}1.509 * * * \\
(0.573)\end{array}$ & $\begin{array}{c}1.448^{* *} \\
(0.664)\end{array}$ \\
\hline edu & $\begin{array}{c}0.373 \\
(0.396)\end{array}$ & $\begin{array}{c}0.609 \\
(0.419)\end{array}$ \\
\hline lngdzc & $\begin{array}{c}0.465^{* *} \\
(0.187)\end{array}$ & $\begin{array}{c}0.668 * * * \\
(0.208)\end{array}$ \\
\hline fine & & $\begin{array}{c}-0.215^{* *} \\
(0.0877) \\
\end{array}$ \\
\hline _cons & $\begin{array}{l}-1.202^{*} \\
(0.938) \\
\end{array}$ & $\begin{array}{c}-2.258^{* *} \\
(1.067) \\
\end{array}$ \\
\hline $\mathrm{N}$ & 119 & 119 \\
\hline $\mathrm{R} 2$ & 0.967 & 0.963 \\
\hline
\end{tabular}


Table 3 shows the results of using Stata14 to regress the financial development scale, financial development efficiency and poverty alleviation through fixed effect model.

\subsection{Analysis of empirical results.}

Financial development scale and poverty reduction. It can be seen that the scale of financial development in ethnic areas is positively related to the poverty alleviation, that is, the increase in the scale of financial development is conducive to the poverty alleviation. The coefficient of lngdp is 0.554 means every $1 \%$ increase in economic growth, poverty is reduced by $0.554 \%$. The coefficients of agr , urbanization level(czh), and fixed asset investment (lngdzc) are positive and statistically significant, indicating that these factors are positively correlated with poverty alleviation, and the effect of urbanization on poverty alleviation is stronger. The educational level $(e d u)$ has a positive effect on poverty alleviation, but it is not significant, indicating that although ethnic areas have higher investment in education aimed at improving the level of human capital, human capital levels have not played a role in poverty alleviation due to the loss of human capital.

Financial development efficiency and poverty reduction. The efficiency coefficient of financial development in ethnic areas is -0.215 , which indicates that the financial development efficiency of ethnic areas is negatively correlated with poverty alleviation; ethnic areas are located in remote mountainous areas, most of them are mainly farming and animal husbandry, and the production cycle is long, the improvement of the financial development efficiency has increased the repayment costs for the poor, which is not conducive to poverty alleviation. At the same time, financial resources in poverty-stricken areas have been excessively out-flowed, and there is an inversion mechanism of "poor and rich". The coefficient of lngdp is 0.601 , that is, for every $1 \%$ increase in economic growth, poverty is slowed down by $0.601 \%$. The coefficient of industrial structure (agr), urbanization level (czh), and fixed asset investment lngdzc is positive and statistically significant. The effect of education level on poverty alleviation is also not obvious.

\section{Conclusions and recommendations}

This paper uses the panel data of seven ethnic provinces and areas in China from 2000 to 2016 to analyze the relationship between financial development scale vinancial development efficiency and poverty reduction. The results show that the scale of financial development is positively correlated with the poverty reduction, however, the efficiency of financial development is negatively correlated with it. The economic growth has a significant positive effect and it can be applied to the poor through the trickle-down effect. There is a significant positive correlation between industrial structure, urbanization level, fixed asset investment and poverty alleviation. The level of urbanization has a greater effect, while the educational level of ethnic areas has no significant effect.

The conclusions have important significance for how to effectively improve the financial service level in poverty areas:

Adjusting the business mode of financial institutions, and establishing a characteristic financial system that is compatible with the local economy characteristics. Breaking the situation of rural credit cooperatives in poverty-stricken areas in ethnic areas and encouraging to develop local small and medium-sized financial institutions, introduce community banks or village banks, and promote collaborative development among these organizations.

Financial institutions in ethnic areas should promote product innovation, vigorously develop inclusive finance, and increase credit input to poor groups. Ethnic areas are rich in tourism resources, it is important to increase financial support for the tourism industry, promote financial poverty reduction and promote industrial development, and thus alleviate regional poverty.

Improving the industrial structure of ethnic areas, speeding up the process of urbanization; strengthening the investment in fixed assets in ethnic areas; and improving the level of infrastructure construction. Improve the human capital level, increase its stock in the region, transform the human resource advantage of the poverty-stricken areas into the advantage of human capital, and create conditions for poverty alleviation in ethnic areas. 


\section{Acknowledgement}

This research was financially supported by Southwest Minzu University Graduate Innovative Research Project (No. CX2016BS03).

\section{References}

[1] Burgess R, Pande R. Can Rural Banks Reduce Poverty? Evidence from the Indian Social Banking Experiment. American Economic Review, 2004, 95(2):781-794.

[2] Claessens S, Feyen E. Finance and Hunger: Empirical Evidence of the Agricultural Productivity Channel. Social Science Electronic Publishing, 2016:1-48(48).

[3] Beck T, Demirgüçkunt A, Levine R. Finance, inequality and the poor. Journal of Economic Growth, 2007, 12(1):27-49.

[4] Jiangang Peng, Guanzheng Li.An Empirical Analysis of the Internal Relationship between China's Financial Development and Dual Economic Structure. Financial Research, 2006(04):90-100.

[5] Yongbin Lu, Peipei Zhao .China's Rural Financial Development and Anti-Poverty Performance: Based on Empirical Evidence from 2003 to 2010. Agricultural Economic Issues, 2014, 35(01): 54-60+111.

[6] Tingting Xie, Yanfang Guo .Spatiotemporal Differences and Influential Factors of Financial Anti-Poverty Efficiency in Ethnic Areas.Journal of Xinjiang University, 2016, 44(02):48-55.

[7] Zhaoyang Lu .Study on the Anti-Poverty Effect of Rural Financial Development in Ethnic Areas.Rural Economy, 2016(01):95-102.

[8] Yanjuan Cui.", Financial Development, Urbanization and Poverty Alleviation: Estimation with System GMM", Lan zhou xue kan,2014(08) 